\title{
La manufactura de hilados y tejidos en la historiografía mexicana, siglos XVIII y XIX. Obrajes, protoindustrias, empresariado y fábricas textiles
}

\section{The Manufacture of the Spinning and Weave in the Mexican Historiography in the 18th and 19th \\ Centuries. Handiwork, Protoindustrialization, Enterprise and Textile Factory}

\author{
Mario Trujillo Bolio \\ Centro de Investigaciones y Estudios Superiores en Antropología Social, México \\ trubolio@ciesas.edu.mx
}

Resumen: El propósito de este artículo es hacer una revisión puntual sobre la historiografía que aborda temas y problemas relativos a la manufacturera textil en la sociedad novohispana y el México independiente. Emprende un análisis crítico que condensa las distintas obras sobre los obrajes en Puebla, Querétaro, Texcoco, Tlaxcala, Coyoacán y San Ángel, así como las formas de producción protoindustriales que permitieron la fabricación de paños de lana en Nueva España. Contempla un detenido estudio de la proliferación de trabajos que se han ocupado en dilucidar el significado de la producción de hilados y tejidos en las distintas regiones del México decimonónico. Se destacan, además, los temas más sobresalientes que se desprenden de la producción manufacturera en las llamadas protofábricas como en centros fabriles que elaboraron hilados y tejidos de lana y algodón. También se diferencia el contenido de las contribuciones que se han ocupado de distinguir distintas fases de la industrialización textil mexicana y del surgimiento de un empresario textil en los estados 
de Puebla, México, Nuevo León, Jalisco, Ciudad de México y sus alrededores, Michoacán y Guanajuato.

Palabras clave: obrajes; Nueva España; protoindustrialización; protofábricas; producción manufacturera; lana y algodón; empresariado textil; siglo xix.

Abstract: The article's objective is to make a critical review of historiography the approaches the topics and problems related to the textile manufacture in the New Spanish society and the later independent Mexico. It undertakes a critical analysis, which concentrates the different paper about manufacture and workshops in Puebla Queretaro, Texcoco, Coyoacan, and San Angel, as well as the types of protoindustrial production, which enabled the fabrication of wool cloth in New Spain. It contemplates a detailed study of the numerous investigations have elucidated the significance of the spinning and fabric production in the different regions of the Nineteenth Century Mexico. In this report some topics stand out, especially those about the manufacture production in the socalled protofactories and the industrial centers, where spinning and fabric of wool and cotton were produced. The content of the contributions about the distinct phases of the industrialization of Mexican textile is differentiated from the rise of Mexican textile entrepreneurs in the States of Puebla, México, Nuevo Leon, Jalisco, Mexico City and the Metropolitan Area, Michoacan and Guanajuato.

Key words: manufacture handiwork; New Spain; protoindustrialization; protofactory; manufacture; wool and cotton; textile enterprise; 19th century.

Fecha de recepción: 9 de febrero de 2015 Fecha de aceptación: 7 de marzo de 2016

\section{INTRODUCCIÓN}

on considerables los aportes historiográficos relativos a la reconstrucción $\checkmark$ de la actividad fabril en el ramo de hilados y tejidos de Nueva España y en el México independiente. Por ello resulta interesante hacer un examen 
detenido sobre los estudios que se han ocupado entre los años que van de 1970 a 2016 del entorno de la sociedad novohispana, pues son significativas las obras publicadas sobre la actividad de los obrajes en el periodo colonial. Igualmente, es válido realizar un balance sobre el quehacer histórico que ha caracterizado las diferentes fases que ha guardado la industria textil dentro del propio proceso de acumulación de capital vivido en la nación mexicana. Lo mismo podría decirse sobre las variadas e interesantes aportaciones que analizan el surgimiento de mercaderes y las especificidades que permitieron la conformación de empresarios que invirtieron en la manufactura textil mexicana en el transcurso del siglo XIX.

En consecuencia, el objetivo de este artículo es evaluar el contenido de aquellos ensayos que han publicado historiadores mexicanos y extranjeros sobre tres temáticas esenciales que nos parecen primordiales e importantes. La primera es aquella que estudia los obrajes en los procesos de protoindustrialización de la lana y seda en Nueva España. La segunda trata de centrarse en la distinción de las características que muestra la reconstrucción histórica sobre el surgimiento y evolución de las fábricas de hilados y tejidos que se establecieron en varias regiones de México. La tercera contempla un detenido balance de las contribuciones históricas que han hecho un seguimiento pormenorizado de aquellas firmas y sociedades mercantiles que en la nación mexicana constituyeron centros fabriles en el ramo textil, sea en la creación de protofábricas, o bien, en la fundación de centros fabriles dedicados a la producción en serie de manufactureras con fibras de lana y algodón.

Cabe decir que en este ensayo se incluye, además, una valoración sobre las diversas fuentes primarias utilizadas por los historiadores en sus respectivos trabajos y que aparecen en el contenido de libros, artículos de revistas y tesis que, conjuntamente, han permitido comprender de manera enriquecedora la evolución de la industria textil mexicana.

\section{PROTOINDUSTRIA, PECULIARIDADES DE LA MANUFACTURA Y EL MERCADO DE UNA INDUSTRIA LANERA}

Existe un referente sobre el origen del proceso de industrialización mexicano con valiosos estudios históricos en donde, desde distintas perspectivas, se ha

\section{()(1) $\$$}


abordado la imbricación alcanzada por las formas de producción protoindustriales dentro del peculiar proceso que adquirió la acumulación originaria de capital en México. Adentrarse a partir del concepto de protoindustrialización en el análisis de la manufactura de la lana resulta importante en términos metodológicos, pues se dispone de una considerable discusión historiográfica en trabajos que han permitido de manera detenida contextualizar y comprender los procesos manufactureros que evolucionaron en la industria de los hilados y tejidos. ${ }^{1}$

Los primeros ensayos referidos al progreso de la manufactura textil mexicana podemos enmarcarlos en cuatro trabajos. Un ensayo pionero interesado por estudiar el proceso de la manufactura en las formas de producción del capitalismo mexicano lo realizó el historiador Luis Chávez Orozco (1936), a partir de su sugerente texto que intituló El obraje, embrión de la fábrica. Su aporte consistió en discutir sobre la posibilidad de que se presentara un continuo proceso en la manufactura textil en el transcurso de los siglos XVIII y xIx. Lo anterior, entonces, permitió que otros historiadores profesionales comenzaran a indagar si la producción de hilados y tejidos en los obrajes llegó a ser un proceso manufacturero incesante con características propias que, a lo largo del tiempo, conoció modificaciones sustanciales que permitieran la creación de fábricas productoras de hilados y tejidos de lana, algodón y seda. Otra contribución interesante para el conocimiento de la manufactura textil mexicana es el trabajo de Manuel Carrera Stampa (1939), titulado "Los obrajes de indígenas en el virreinato de la Nueva España”. La importancia del estudio radica en que advirtió que la producción manufacturera en los obrajes se realizó a través de la sobreexplotación de la fuerza de trabajo de comunidades indígenas y también a través del trabajo compulsivo que se les impuso a los presidiarios.

${ }^{1}$ Nos parece conveniente señalar que la historiadora inglesa Maxine Berg (1987) es quien, desde nuestro punto de vista, ha precisado de manera objetiva y a partir de elementos teórico-metodológicos el estudio sobre los modelos de la manufactura del algodón, lana, seda y lino. Y todo, a partir de los procesos de acumulación primitiva de capital y del modelo productivo conocido como protoindustrialización. También es importante señalar la consideración de esta autora del por qué incluyó, en este proceso, la especificidad que cobró la organización de la fuerza laboral en la producción textil, y ya sea a partir del trabajo a domicilio, a través de las redes del régimen de putting-out, o bien, bajo el sistema fabril mecanizado que, en conjunto, hicieron posible la manufactura de los hilados, tejidos y ropa (pp. $88-96$ y $241-244)$.

\section{()(1) $\$$}


Se tienen otros dos trabajos más realizados por historiadores estadunidenses interesados en las características que adoptó la protoindustrialización en la economía novohispana. Nos referimos al ensayo de Richard E. Greenleaf (1967) titulado "The obraje in the late Mexican colony". En el mismo presentó un interesante aporte al ocuparse por caracterizar la forma de producción de la manufactura de la lana y su presencia como actividad productiva en el mercado de Nueva España. También se cuenta con la contribución de John Super (1976) con el artículo titulado "Queretaro obrajes: industry and economy in early provincial Mexico, 1600-1810". Este autor, en su análisis histórico de las actividades productivas novohispanas, trató de discernir sobre las peculiaridades de una región con gran presencia de producción obrajera y, al mismo tiempo, fue de los primeros en determinar que esta actividad productiva tuvo gran importancia en el orden colonial de Nueva España.

La historiografía sobre la manufactura textil mexicana que se produjo durante las décadas de 1980 y 1990 contó con un avance considerable gracias a historiadores profesionales mexicanos, estadunidenses e ingleses adscritos a centros de enseñanza superior. Su propósito consistió en estudiar los aspectos laborales y el proceso productivo en los obrajes. Aquí, podemos iniciar con las contribuciones del historiador Alberto Carabarín Gracia (1984; 1992), quien se centró en el estudio de la zona obrajera poblana colonial. Sus aportes se caracterizaron por presentar una evidencia empírica construida a partir de la consulta documental primaria. A partir de ello, este autor dio a conocer las características de la fuerza laboral del obraje en la provincia novohispana de Puebla en su manuscrito El trabajo y los trabajadores del obraje en la ciudad de Puebla, 1700-1710, y además, en otro ensayo, "Región y mercado colonial: las coyunturas de los obrajes poblanos entre los siglos XVI y XVIII". En este último estudio se logra discernir en el espacio novohispano la importancia de los trabajadores obrajeros en la manufactura de la lana realizada en la ciudad de Puebla y sus alrededores.

El enriquecimiento del debate referido al conocimiento específico sobre los obrajes cobró vigor a partir del artículo que publicara Manuel Miño (1989) y que, intitulara, a partir de la siguiente pregunta: “Protoindustria colonial?" Con este ensayo el autor no sólo promovió la discusión sobre el contenido del incipiente proceso de industrialización en diversas regiones del capitalismo mundial, sino, a su vez, intentó demostrar bajo el método

\section{()(1) $(3$}


comparativo las formas establecidas que guardó esta forma de producción en los dos entornos de las economías como la Nueva España y el Perú colonial. ${ }^{2}$ Para el caso de la producción de hilados y tejidos novohispanos, es sugerente lo que Miño (1990) advirtió:

Entre 1570 y 1620 el panorama del trabajo textil parece reorientarse. La comunidad indígena, reducida o congregada en pueblos o en permanente lucha por conseguir el status de tal, se encontró nuevamente impulsada a realizar una producción para el mercado a través de corregidores y alcaldes mayores: el repartimiento será el nuevo eje articulador de la producción y circulación de la mercancía textil en el caso del algodón, particularmente en el sur de la Nueva España.

En tanto que para el caso de la manufactura de textiles, este autor también nos dice lo siguiente:

fue una forma de producción con un alto nivel de división del trabajo y un funcionamiento semiautónomo de la propiedad agraria en Nueva España, perfectamente articulado a ella en el caso del espacio andino. Este tipo de organización tuvo una vinculación relativa con la comunidad indígena, en el primer caso, adscrita solo al hilado, como sucedió en varios casos de obrajes de Tlaxcala, Tacuba, México o Querétaro en distintos momentos (p. 40).

Posteriormente, Miño (1990, pp. 257-285 y 286-344) en su obra abundó todavía más en aspectos esenciales relativos al funcionamiento de los obrajes y relacionados con el abastecimiento de materia prima, la organización productiva, los sistemas de trabajo, jornales, producción y circulación de las manufacturas. Con todo, este autor llegó a la conclusión que históricamente hay que distinguir los distintos momentos de la actividad textil novohispana a partir del llamado trabajo a domicilio y la concentración laboral obrajera. ${ }^{3}$

${ }^{2}$ Véanse al respecto las obras de Miño (1989; 1990; 1993a; 1993b).

${ }^{3}$ Esta diferenciación la reconstruyó Miño con materiales documentales provenientes del Archivo General de la Nación de México -en los ramos Tierras, Padrones, Aduanas, Intendentes-, Archivo General de Notarías de la Ciudad de México, con el Archivo de la Corte Suprema de Justicia, Archivo del Antiguo Ayuntamiento y Archivo General del Estado de Tlaxcala. 
En esta investigación se diferenciaron aquellos momentos en que se presentó el estancamiento de la producción obrajera. No obstante, Miño no dejó de advertir que en la manufactura del algodón hubo algunos momentos de renovación en distintas regiones del entorno novohispano en donde tuvo cabida la actividad obrajera.

La reconstrucción historiográfica relativa a los procesos de protoindustrialización en el rubro específico de la manufactura de textiles cuenta con otras obras interesantes consideradas fundamentales. Hay que referirse al trabajo de Carmen Viqueira (1983), quien primeramente ofreció un panorama general sobre el surgimiento de la producción de hilados y tejidos, a través de un ensayo titulado "Los orígenes de la industria textil en México". Sin embargo, después apareció un libro que conjuntamente escribieron Carmen Viqueira y José I. Urquiola (1990) que intitularon Los obrajes en la Nueva España, 1730-1630. Este último estudio es una loable investigación pues cubre un periodo de larga duración donde el lector puede advertir un panorama de la producción de la manufactura de sayales de lana en los obrajes de paños que durante el periodo colonial se esparcieron por distintos entornos manufactureros que evolucionaron en las villas de Querétaro, Tlaxcala, Puebla y Texcoco. ${ }^{4}$ El aporte que ofrece este texto se constata en la indagación que los autores hicieron para demostrar lo que fue la significativa presencia de la manufactura de la lana en la propia organización en el centro de la economía de Nueva España, la movilidad de trabajadores obrajeros, el trabajo de hilanderas y la presencia de matrimonios que se ocupaban como tejedores en los obrajes (pp. 158-161).

Respecto a la caracterización que históricamente se ha realizado sobre el obraje novohispano, podemos continuar el recuento con una obra que enriqueció aún más el conocimiento de la manufactura de textiles novohispana. Nos referimos a la contribución de Richard J. Salvucci (1992) titulada Textiles y capitalismo en México. Una historia económica de los obrajes, 1539-1840. ${ }^{5}$ Hay

${ }^{4}$ La factura del libro se realizó con un exhaustivo análisis documental proveniente de valiosos archivos, como el General de la Nación de México -los ramos Indios y Mercedes-, del General de Indias, en Sevilla, y con el Archivo Histórico de Querétaro, ramo Notarías Civiles.

${ }^{5}$ El libro de Salvucci (1992) sobresale particularmente en la historiografía por la indagación en acervos existentes fuera de México, como el Archivo General de Indias, Sevilla -en sus ramos Contaduría, Indiferente general y México-; en los archivos estadunidenses existentes en el National Archives and Records Service; en Washington, en la Public Library of

\section{()(1) $(3$}


que advertir que el conocimiento histórico presentado en el libro consistió en dar una visión global de lo que fue el entorno productivo de los obrajes novohispanos, y remitiéndose concretamente a los que se establecieron en el Valle de México, el Bajío, así como en la cuenca de Puebla-Tlaxcala.

En todo caso aquí habría que preguntarse por qué este trabajo destaca historiográficamente. La respuesta puede encontrarse precisamente en que este autor buscó polemizar sobre lo que planteó el trabajo antes citado de Luis Chávez Orozco con el propósito de reflexionar críticamente si el obraje resultó ser el embrión o germen de la producción fabril, ${ }^{6}$ e incluso, si este tipo de establecimiento manufacturero se puede enmarcar en lo que sería una forma de producción protoindustrial. A este respecto, Salvucci (1992, pp. 82-83) argumentó que para entender lo que fue el complejo entorno de la producción obrajera es necesario remitirse y comprender toda un serie de aspectos que el historiador debe incluir en un análisis histórico y que necesariamente debe contar con los siguientes aspectos: la especificidad de los mercados coloniales; el cambio tecnológico; los precios de los paños; la distinción entre un trapiche y un obraje; los procesos de manufactura -limpiado y preparación de la lana, el teñido, tejido, abatanado y terminado-; la misma forma en que se dio la explotación sistemática de la fuerza de trabajo, ya sea la indígena, esclava, o bien, la proveniente de los reos recluidos en los obrajes. Salvucci (1992), para darle respuesta a los planteamientos anteriores, hizo una interesante recopilación y análisis de estadísticas de producción, empleo y telares para tratar de medir su real capacidad productiva. En consecuencia, este autor fue muy específico cuando argumentó claramente que "es incorrecto considerar al obraje como una fábrica primitiva, porque la razón de ser de la fábrica era distinta. No es de sorprender que ningún empresario convirtiera un obraje en una fábrica introduciendo maquinaria. El obraje no fue un 'embrión de la fábrica”" (pp. 70-71).

\footnotetext{
New York y, particularmente, en el Rosenbach Museum and Library, de Filadelfia, en donde este autor rescató y dio a conocer la información del interesante expediente Tlaxcala, gremio de tejedores de algodón.

${ }^{6}$ Aquí nos referimos a los interesantes trabajos de Luis Chávez Orozco (1936) tanto al ya mencionado El obraje, embrión de la fábrica, y particularmente al trabajo en el que planteó que el obraje era precisamente el antecedente de la industrialización mexicana, en Historia económica y social de México. Ensayo de interpretación (1938).
}

\section{(ㄷ)(1) $(3$}


Otra tesis fundamental de Salvucci (1992) es concluir en el sentido de que "los obrajes no representaron una protoindustria y mucho menos fueron protofábricas”. Y, más bien, desde el punto de vista de este autor, "los obrajes ilustran la naturaleza dispareja del desarrollo del mercado de Nueva España y sus implicaciones para la economía en general” (p. 98). De esta forma, Salvucci estableció con su libro que el problema es todavía más complejo y que depende de muchos factores en un determinado proceso histórico que tuvo que ver tanto con el desplome de la industria lanera y, como bien dice: "Pese al papel de los obrajes para abastecer la colonia, su potencial para la transformación en empresa industrial fue limitado. Su caducidad tecnológica, significativa a la luz de la revolución industrial fue limitada" (p. 257).

En términos analíticos también el historiador inglés Guy Thomson tuvo la preocupación por estudiar la manufactura textil en México. Si bien en una contribución hizo un recuento crítico respecto al proceso de protoindustrialización que se presentó en las obras tanto de Miño como de Salvucci, en su trabajo "Continuidad y cambio en la industria textil manufacturera mexicana, 1800-1870" (1999) nos aporta un planteamiento interesante al establecer que en la formación de la nación mexicana entre el proceso de transformaciones y persistencias sí tuvo cabida la producción manufacturera de lana, pues dice que "se sobrepuso al impacto de la independencia, la producción pasó de grandes unidades a unidades más pequeñas y de áreas centrales a la periferia". Thomson (1999, pp. 61-67) incluso concluye en su investigación que "algunos obrajes sobrevivieron y en Puebla hubo por lo menos un intento exitoso de 'transformación' (es decir, la mecanización de hilado en la forma tradicional del obraje)". Otro aporte de este autor es el haber diferenciado que en las postrimerías de la colonia había una carencia de ánimos empresariales, sin embargo, advierte que la producción de los tejidos de la lana lograron una recuperación importante en lo que denomina el periodo de precoz intento mexicano de industrialización y que ubica para las décadas de 1830 y 1840 (pp. 77-80).

Desde los primeros años del siglo XXI continuaron apareciendo otros tantos estudios monográficos sobre los obrajes en Nueva España. Ejemplo de ello es la tesis de licenciatura elaborada por Eduardo Adolfo Oropeza (2001) intitulada Del obraje de Contreras a la fábrica de hilados y tejidos La Magdalena. Cuatrocientos años de testimonio textil. Resulta ser una investigación

\section{()(1) $(9$}


que se ocupa en describir las formas que adquirió la fuerza de trabajo en el proceso productivo obrajero. Lo atractivo del estudio es que logró rescatar la importancia que en el mismo tuvieron en la propia división del trabajo del obraje el trasquilador, los limpiadores de la materia prima, los carderos, tintoreros y tejedores. ${ }^{7}$

Otras obras de reciente manufactura y referida a los pueblos fabriles que tuvieron obrajes en Tlalpan y San Ángel los podemos ubicar en los trabajos con un sustento documental y que trataron de hacer un recuento histórico de larga duración. Primero nos referiremos a la obra que presentó Yolanda Dolores Terán Trillo (2012) titulada El castillo de La Fama. Antiguo molino de trigo y fábrica de hilados y tejidos en Tlalpan, 1612-1936. La autora logró reconstruir el diseño arquitectónico, el proceso productivo que permitía la obtención de harina, la tecnología que se implementó -aperos, herramientas y sistemas constructivos-, y la utilización del agua en el molino de San Agustín de las Cuevas que más adelante se convirtió en un obraje para la manufactura de paños. ${ }^{8}$

En esta misma perspectiva se cuenta con el trabajo de Teresa Mora Vázquez (2012), Testimonios de Tizapán. Memoria y olvido de un pueblo originario de la ciudad de México. Su objetivo fue rescatar la historia de un pueblo en donde sus habitantes por varias generaciones indistintamente se dedicaron a las labores agrarias y la manufactura textil. Si bien puede decirse que es un estudio que no se respalda necesariamente en fuentes primaras, con el acopio bibliográfico realizado y las técnicas de la historia oral, esta autora buscó reconstruir los rasgos de identidad cultural de los habitantes del pueblo de Tizapán en las últimas décadas del siglo xx.

Así, Mora Vázquez rescata la importancia que tuvo el molino de Miraflores, la fábrica de papel Loreto, y lo que fue la zona textil en San Ángel con los centros manufactureros textiles de La Hormiga, La Corona y La Alpina.

\footnotetext{
${ }^{7}$ La trama empírica de este estudio se construyó con fuentes primarias a partir de lo que fueron transcripciones o actos de visitas de los funcionarios coloniales y que dieron una mirada del mundo fabril del obraje con mayor historia que se estableció en San Ángel en las cercanías de la ciudad de México.

${ }^{8}$ Cabe señalar que esta contribución se logró a partir de información documental proveniente de archivos como el General de la Nación, el de Notarías siglo xix, y el del Registro Público de la Propiedad y Comercio de la Ciudad de México.
}

\section{()(1) $\$$}


En todo caso, lo que sobresale en este aporte es la reconstrucción a través de distintas entrevistas de historias de vida de lo que fue la cultura del pueblo fabril en los establecimientos textiles y fabricación de papel, y que el relato da cuenta de la manera en cómo finalizó entre las décadas de 1960 y 1990 la vida productiva de estos centros manufactureros de hilados, tejidos y ropa en San Ángel.

\title{
PIONERAS RECONSTRUCCIONES HISTÓRICAS DEL PROCESO DE INDUSTRIALIZACIÓN TEXTIL MEXICANO
}

\begin{abstract}
$\mathrm{Al}$ adentrarse el historiador en el conocimiento de los primeros aportes sobre el surgimiento de centros fabriles en distintas regiones y estados del país, el estudioso de los procesos de preindustrialización e industrialización para el México decimonónico se encuentra con estudios que se publicaron desde la década de 1960. Destacan historiográficamente por ser las precursoras en reconstruir el surgimiento de las protofábricas citadinas ${ }^{9}$ y también las fábricas textiles que empezaron a funcionar en distintos entornos fabriles de la nación mexicana.

Un aporte distintivo que inició con el estudio sobre el proceso de industrialización en la rama de hilados y tejidos lo presentó Jan Bazant (1964) con el título, "Evolución de la industria textil en Puebla: 1544-1845". Ya desde la publicación de este artículo, Bazant advertía la existencia de un interesante progreso de la manufactura textil en un corredor manufacturero que cubrió y se manifestó en las provincias de Puebla y Tlaxcala, y no tan sólo para la época colonial, sino que observaba en esta región un proceso fabril que repuntaría con cierto vigor a partir de la manufactura
\end{abstract}

9 Aquí nos referimos a las distintas hilanderías que en las primeras décadas del siglo xix existieron en la ciudad de México y en Puebla con un tipo de organización de producción en cadena y peculiar sistema fabril basado en técnicas de trabajo intensivo, la maximalización de las habilidades y disciplina laboral. A este respecto, Maxine Berg (1987) nos ofrece una definición interesante: "las protofábricas dedicadas al estampado de indianas han sido consideradas como el 'eslabón perdido' entre el sistema protoindustrial y el moderno sistema industrial de las industrias textiles" (pp. 100-101 y 252-253).

\section{()(1) $\$$}


de hilados, tejidos y la hechura de ropa ya desde las primeras décadas del México decimonónico.

Por otra parte, los historiadores Luis Chávez Orozco y Enrique Florescano (1965) publicaron conjuntamente el libro que intitularon Agricultura $e$ industria textil en Veracruz. El objetivo del volumen fue presentar ensayos referidos al cultivo del algodón desde la segunda mitad del siglo XVIII, en las zonas de Acayucan, Tlalixocoyan, Medellín y Cotaxtla, así como indagar cuáles fueron los precios de la fibra veracruzana en el mercado novohispano (pp. 70-89). Asimismo, otro propósito de este libro fue incluir bibliografía y materiales documentales referidos a los rasgos que guardó la producción de los centros de manufactura textil veracruzanos en el siglo xIx, y presentar las encuestas que el Banco del Avío realizó en la década de 1840, referidas a la producción de algodón, lana y seda. ${ }^{10}$

Sin duda, en este balance historiográfico no puede hacerse a un lado un libro clásico sobre los temas que nos ocupan. Nos referimos al presentado por Dawn Keremitisis (1973), La industria textil mexicana en siglo XIX. La autora estadunidense es la primera profesional de la historia que se preocupó en distinguir, para el caso del México decimonónico, cuáles fueron las distintas fases de la producción manufacturera de los hilados y tejidos a partir de las distintas variables, como la tecnología, las plantas de energía, el procesamiento de la materia prima como el algodón, el proceso de trabajo y la realización en el mercado de los hilados y tejidos. ${ }^{11}$ Keremitisis (1973, pp. 20-39 y 80-98) diferenció en qué consistieron las políticas de fomento a esta industria del incipiente Estado mexicano y, de igual modo, nos dio un primer panora-

${ }^{10}$ Cabe decir también que, entre los materiales rescatados en esta recopilación, destaca un ensayo pionero de la fábrica de Cocolapan, aparecido en la publicación El Mosaico Mexicano, en el año de 1841. Véase Chávez y Florescano (1965, pp. 274-278).

${ }^{11}$ Keremitisis analizó en detalle la fuente hemerográfica con periódicos decimonónicos mexicanos: Seminario de la Industria Mexicana, El Fénix y El Siglo XIX. También su investigación destacó por darse a la tarea de cotejar la información de las Memorias de Hacienda, del entonces Ministerio de Hacienda, e igualmente en utilizar y analizar los niveles productivos en los informes estadísticos de la república mexicana que elaborara Emiliano Busto. Al mismo tiempo, la autora llamó la atención por utilizar en su estudio de la rama textil varios directores de comercio como el de Eugéne Maillefert (1992), y acervos en el Centro de Estudios de Historia Condumex -hoy CARso-, el Archivo General de la Nación, y los materiales sobre historia de las industrias, existentes en la biblioteca Lerdo de Tejada de la Secretaría de Hacienda.

\section{(ㄷ)(1) $(3$}


ma de los empresarios individuales, de la forma como se constituyeron las primeras compañías industriales, así como también la inversión de capital en la rama industrial textil.

En la década de 1980 es cuando inicia una copiosa producción historiográfica interesada en estudiar metódicamente a la manufactura textil mexicana. Aparecieron publicados varios trabajos que dieron a conocer con mayor detalle los procesos de preindustrialización y la mecanización de producción textil del México decimonónico. Se puede incluir la cuidadosa obra de Walther L. Bernecker (1992), cuya edición en alemán data de 1987. No obstante, la versión en español se tituló De agiotistas y empresarios. En torno de la temprana industrialización mexicana (siglo XIX). Esta aportación se inscribe en una metodología que busca presentar en qué consistió el proceso histórico de la primera industrialización mexicana. ${ }^{12}$ Las conclusiones a las que llegó Bernecker (1992, pp. 142-148) es que dicho proceso se gesta con las fábricas fundadas en México por lo que denomina nuevos industriales-comerciantes extranjeros que invierten en la fabricación de hilados y tejidos entre los años de 1835-1845.

Hay otras obras que se preocuparon por indagar el proceso de industrialización en el capitalismo mexicano. Una de ellas partió del legado en Historia moderna de México. El porfiriato. Vida económica, de Daniel Cosío Villegas (1985). De la misma se desprende el estudio del progreso económico que se presentó en el México porfiriano, y escrito por Fernando Rosenzweig. Su análisis fue sugerente pues analizó las características de la industria mexicana para México del último cuarto del siglo xix. Rosenzweig (1985) en su trabajo adelantó que durante el porfiriato tardío ya existían grupos de capitalistas muy consolidados que habían adquirido varios centros fabriles en Veracruz, Puebla, Jalisco, y en el Valle de México y que, parte del incremento de sus fortunas, se habían generado desde la primera mitad del siglo xIX. Al remitirse a las inversiones extranjeras que se hicieran en las manufacturas de los hilados y tejidos este autor nos señala lo siguiente:

${ }^{12}$ Para la elaboración y sustento de su trabajo, Bernecker (1992) recopiló y analizó las estadísticas contenidas en las Memorias de Hacienda, e información documental de diversos archivos sobre asuntos exteriores alemanes, británicos, franceses, españoles, y mexicanos, así como reportes consulares e informes diplomáticos, comerciales y económicos.

\section{()(1) $(9$}


El primer paso lo dio en 1889 un grupo de comerciantes franceses de la ciudad de México: entre otros, Enrique Tron, Eugenio Roux y J. B. Ebrad, al construir la Compañía Industrial de Orizaba, S. A. (Cidosa), empresa que adquirió las fábricas de hilados y tejidos de algodón Cerritos y San Lorenzo, esta última de la propiedad de Tomás Braniff, quien pasó a ser socio de la compañía (p. 454).

Respecto a los propietarios que invirtieron en la manufactura textil en el llamado porfiriato tardío, el mismo Rosenzweig (1985) nos menciona:

en 1892, un grupo de capitalistas hispano-mexicanos: Luis Barroso Arias, Ínigo Noriega y Adolfo Prieto, y el capitalista francés Agustín Garcín, compraron las fábricas textiles Miraflores y La Colmena, en el Estado de México, y la de San Antonio Abad, de la Capital. Esta última la había construido en 1883 el inversionista español Manuel Ibáñez, quien en 1885 la vendió a Noriega. Así nació la compañía Industrial San Antonio Abad, cuyo capital ascendía en 1910 a tres y medio millones de pesos (p. 455).

El otro trabajo pionero de investigación que se remite a la acumulación originaria de capital es el que hiciera, desde una perspectiva marxista, Sergio de la Peña (1975) y que intitulara La formación del capitalismo en México. En este trabajo aparece un breve repaso sobre las formas de producción basadas en la manufactura de hilados y tejidos. Peña (1975, pp. 145-154) le dio importancia e incorporó en su análisis a los sectores productivos que propiciaron la industrialización mexicana $y$, en su indagación, le dio un papel destacado a la manufactura textil a partir de la segunda mitad del siglo xix en la misma conformación del mercado interno mexicano.

\section{SOBRE LOS ESTUDIOS REGIONALES DE LA INDUSTRIA TEXTIL MEXICANA EN EL SIGLO XIX}

Una tendencia por realizar estudios económico-sociales sobre las regiones y los espacios fabriles del México decimonónico, se manifestó con investigaciones procedentes de instituciones mexicanas de enseñanza superior.

\section{(ㅇ)(1) $\$$}


Las mismas cobraron fuerza en las décadas de 1980 y 1990, y que aun siguen realizándose en los primeros 16 años del siglo xxI. La importancia de todas las contribuciones radica en que incluyeron en sus variados ensayos el surgimiento y evolución de los procesos de industrialización en el ramo de los textiles. Sin duda, el acervo es vasto y comprende libros de autoría única, capítulos recopilados en volúmenes colectivos, artículos de revistas y tesis de posgrado que, en conjunto, ya han cubierto la historia de la manufactura textil en varios estados de la república mexicana.

Guillermo Beato y Raquel Beato King en sus respectivos artículos, "La industria textil fabril en México", t. I: 1830-1900, y t. II: 1900-1910, fueron los que emprendieron un estudio crítico y de larga duración de la fabricación textil a nivel nacional dividiéndola a partir de las regiones norte, centro y sur. La importancia de este trabajo radicó en el balance cuantitativo para dar una visión retrospectiva del comportamiento de esta rama industrial a partir de un balance estadístico (Beato, 2003, pp. 213-228). Lo interesante del aporte es que determinaron los momentos ascendentes, retrocesos y complicaciones que presentaron en el transcurso del siglo xix la manufactura de hilados y tejidos (Beato King, 2003, pp. 247-254).

Se cuenta con otros estudios que, por su calidad, queremos incluir en este balance historiográfico, y que cubren Michoacán, considerables aportes sobre Puebla, algunos referentes a Jalisco, Tlaxcala, Veracruz, Estado de México, Nuevo León, Valle de México y Nayarit. De manera cronológica por el año de su publicación podemos iniciar con el libro de José Alfredo Uribe Salas (1983), La industria textil en Michoacán 1840-1910. Esta obra se remite a los orígenes de la industria textil michoacana desde sus antecedentes en los obrajes y la manufactura de la seda. El periodo que el autor establece -entre 1860 a 1910 - es cuando cobra relevancia en Michoacán la industria del algodón, lino, lana y seda (pp. 99-133). Por ello, Uribe reconstruyó quiénes fueron los inversores de las fábricas y cuál fue la vida fabril de los establecimientos manufactureros como los de La Paz, La Unión en Morelia de Paraíso, La Providencia, San Pedro Hurtado y Cerda en Uruapan, así como la Compañía Industrial la Virgen en Tajimaroa. ${ }^{13}$

${ }^{13}$ Lo valioso del trabajo de Uribe Salas es que en su hechura contó con una indagación detenida del Archivo del Registro Público de la Propiedad de Michoacán, del Archivo del Ayuntamiento de Zamora, y la exhaustiva búsqueda de información en los periódicos es-

\section{()(1) $\$$}


Aquí se puede diferenciar lo que fue la obra pionera de Guy Thomson (1989), Puebla de los Ángeles. Industry and society in a Mexican city, 17001850. También cabe mencionar los artículos de Humberto Morales (1987, 2009), el primero que tituló "La expansión industrial del valle de Atlixco a fines del siglo XIX. El caso de la fábrica textil de Metepec de la CIASA". De igual modo, su interesante trabajo: "La industria textil mexicana en el ciclo de las exportaciones latinoamericanas: 1880-1930. Política fiscal y de fomento en la encrucijada de la revolución". Respecto a los recientes estudios que se han realizado sobre este mismo estado se tiene el publicado por Sergio Rosas Salas (2013), "Agua e industria en Puebla. El establecimiento de la fábrica textil La Covadonga, 1889-1897", y que incluye otros aspectos relacionados con la energía hidráulica y el contexto de un determinado entorno fabril. ${ }^{14}$

Existen someras contribuciones relativas a la evolución de la industria textil en Tlaxcala y que se pueden ubicar en dos publicaciones. En primera instancia, queremos referirnos a la compilación de trabajos que hiciera Alba González Jácome (1991) en el libro La economía desgastada. Historia de la producción textil en Tlaxcala. ${ }^{15}$ En él podemos encontrar sucintos estudios monográficos para la zona textil tlaxcalteca y sus diferentes centros manufactureros en el estado y que llegaron a fabricar hilados y tejidos en los siglos XIX y $\mathrm{xx}$. Asimismo, la investigación histórica sobre la manufactura de telas y ropas en Tlaxcala continuó con estudios específicos de centros fabriles. Milena Kopriviza Acuña (2008) coordinó un número temático de la revista Thahuilo titulado, La industria textil en Tlaxcala también con sucintos ensayos. ${ }^{16}$

tatales Periódico Oficial, El Grano de Arena, Gaceta Oficial, La Voz de Michoacán, entre otros consultados.

${ }^{14}$ Cabe subrayar que este trabajo, para lograr reconstruir los orígenes y evolución de esta empresa textil, recurrió a fuentes primarias de los acervos existentes en Puebla sobre la industria de hilados y tejidos, y al Archivo Histórico del Agua en su rico ramo documental Aprovechamientos superficiales.

${ }^{15}$ Fueron analizados en los trabajos sobre un centro manufacturero en particular como el de Jaqueline López Villafañe, "Talleres y fábricas pequeñas en Santa Ana Chiautempan". Al mismo tiempo, en este texto aparece el breve ensayo de Olga Rodríguez, "Una industria textil moderna en Santa Ana Chiautempan”. Igualmente, cuenta con el aporte de Lilia Gutiérrez Zanatta con un artículo muy sucinto, "Las fábricas textiles de la margen Norte del río Zahuapan: La Trinidad".

${ }_{16}$ Algunos aportes destacados podrían ser los breves artículos de los centros fabriles tlaxcaltecas. Nos referimos al ensayo de Virginia Polvo Escobar, "El Valor, una aproximación

\section{()ㅜ(1) $\$$}


Para el caso del estado de Veracruz se tienen los trabajos sobre la industria textil que tuvo cabida en el valle de Orizaba. Se cuenta con el libro precursor de Bernardo García (1981), Un pueblo fabril del porfiriato: Santa Rosa, Veracruz. Resulta ser un estudio completo de los hombres de negocios originarios de la región barcelonette y fundadores de la Compañía Industrial Veracruzana (CIVISA). El libro es pionero en enmarcar en un análisis histórico las relaciones obrero-patronales a partir de la documentación contenida en el archivo de lo que fue esta gran empresa (pp. 25-39 y 97-129).

Se tiene interesantes trabajos para la conformación de la industria textil en Veracruz. Aquí nos queremos referir particularmente a los estudios de Aurora Gómez-Galvarriato. Primero tenemos el que apareció como un avance de investigación que intituló "Industrial development in time under institutional frailty: The Mexican cotton textile industry in the 19th. century" (1998). Otros estudios de Gómez-Galvarriato (1999) es su tesis doctoral, The impact of the revolution: business and labor in the Mexican textile industry Orizaba, Orizaba, Veracruz, 1900-1930. Una contribución de esta autora que nos interesa destacar es que incursionó en el análisis econométrico para llegar a cuantificar el proceso de industrialización de la rama textil mexicana entre los años de 1855 a $1872 .{ }^{17}$ De Gómez-Galvarriato (2013) hay que considerar al mismo tiempo su libro Industry and revolution. Social and economic change in the Orizaba valley, Mexico. Lo innovador de esta obra es que en la reconstrucción histórica recurre a variables como población, mercado, tradición artesanal en la manufactura textil, y proteccionismo gubernamental a la naciente industria en la región textil veracruzana. ${ }^{18}$

para el estudio de la fábrica más antigua de Tlaxcala"; al de María Clemencia Botello, "Fábrica La Josefina detrás del telón". De igual modo, sobresalen los de Mario Bojalil, "Fábrica de hilados, tejidos y estampados San Luis"; de Rocío Velázquez, "Fábrica Zahuapan, hilados y tejidos"; y de Carmen Meza, "Fábrica textil La Estrella, Amaxac de Guerrero -Santa Ana Chiautempan". Todos incluidos en la revista Tlahcuilo, núm. 4, enero-marzo de 2008 -que en ese entonces publicaba el Boletín del Archivo Histórico del estado.

${ }^{17}$ Su estudio partió de fuentes documentales estadunidenses provenientes de Commerce and Navigation Reports, de los reportes de tarifas de la aduana marítima y fronterizas, y de los censos del departamento de comercio. Gómez-Galvarriato (1998, p. 18).

${ }^{18} \mathrm{La}$ importancia de los aportes que sobresalen en los demás trabajos de Gómez Galvarriato, radica en que tuvo acceso directo al archivo de Río Blanco de la misma empresa Cidosa, para reconstruir y dar cuenta de cuál fue, entre el porfiriato y la revolución, tanto la capacidad productiva que alcanzó esta empresa textil, como el hecho de hacer un análisis detenido de los salarios de este importante centro fabril.

\section{()(1) $\$$}


Desafortunadamente se han rescatado solamente breves historias sobre centros fabriles de la manufactura de hilados y tejidos de lana y algodón que productivamente evolucionaron en el siglo xix en el Estado de México. Se cuenta con los libros de Margarita García Luna (1984), en el cual hay un intento por rescatar solamente algunos aspectos de la actividad fabril del estado. Aquí nos referimos a su texto El movimiento obrero en el Estado de México. Primeras fábricas, obreros y huelgas (1830-1910). En el mismo se describe de manera escueta el surgimiento de fábricas en Tlalnepantla, Monte Bajo, Chalco, y el centro fabril El Progreso en Arroyozarco. También García Luna (1998) se dio a la tarea de publicar un encomiable libro de difusión que cuenta con excelente material fotográfico sobre las fábricas y que podemos incluir en este balance historiográfico, Los orígenes de la industria en el Estado de México 1830-1930.

Al iniciar la primera década del presente siglo prosiguieron los estudios de la industria textil para el Estado de México y el Distrito Federal. ${ }^{19}$ Aquí podemos incluir dos interesantes aportes que estudian detalladamente los centros fabriles en el Valle de México. Nos referimos a la obra de José Gustavo Becerril, titulada Las fábricas de San Antonio Abad y San Ildefonso (1842-1910). Producción y tecnología en la manufactura de hilados y tejidos de algodón y lana (2011a), y su tesis doctoral Innovación tecnológica en la mecanización de la industria textil del Valle de México 1880-1910. Transformaciones y permanencias productivas en las fábricas de hilados y tejidos de algodón (2011b). En ambos trabajos se rescata la inversión de capitales, la implementación de tecnologías modernas y se da cuenta de cómo los centros fabriles lograron una racional mecanización en las distintas fases de los sistemas manufactureros en la industria de la lana y el algodón (Becerril, 2011a, pp. 71-81 y 123-151).

Finalmente, podemos decir que aún continúan elaborándose tesis de posgrado referidas a la temática de hilados y tejidos. Un ejemplo de ello es el trabajo de Javier Vizcarra Rubio (2011) titulado Estructura, funcionamiento y rentabilidad de la empresa textil tepiqueña y de otras regiones del México porfi-

19 También aquí puede mencionarse el trabajo sobre la fabricación de hilados y tejidos en donde se incluye detenidamente el estudio de la mujer trabajadora en la manufactura textil, como la obra que presentara Carmen Ramos Escandón (2004), Industrialización, género y trabajo femenino en el sector textil mexicano: el obraje, la fábrica y la compañía industrial.

\section{()(1) $\$$}


riano. Este es un interesante estudio sobre los empresarios textiles en Tepic con base en el archivo histórico de la fábrica textil Bellavista, y relaciona la actividad manufacturera que se dio en Nayarit y Colima con las de Jalisco, Valle de México, Veracruz, Tlaxcala y Querétaro.

\section{EL QUEHACER DE HISTORIAS DE EMPRESARIOS INVERSORES EN LA INDUSTRIA TEXTIL}

Un importante referente de la historia empresarial de los hilados y tejidos en México es el trabajo que abrió el camino en el estudio del empresariado textil escrito por Howard F. Cline (1947), "The 'Aurora Yucateca' and the spirit of enterprise in Yucatan, 1821-1847". Cline elaboró su ensayo a partir de documentos y cartas de los socios propietarios y fundadores de este centro fabril como lo fueron Pedro Sainz de Baranda, John L. MacGregor y John Burke. A este autor se le debe el primer intento por reconstruir la forma en que funcionaron los centros fabriles como el que se estableció en la población de Valladolid. Cline elaboró la reconstrucción de los empresarios con base en la revisión de las estadísticas realizadas por José M. Regil y Alonso Manuel Peón. Sus indagaciones lo llevaron no tan sólo a establecer que en La Aurora Yucateca la producción manufacturera de algodón se logró con la importación de maquinaria proveniente de Nueva York, sino además que en la elaboración de mantas participaron familias indígenas mayas cuya experiencia en la manufactura de hilado y tejido se remonta al periodo colonial yucateco, sea bajo la forma de tributo, o bien, a partir de la explotación de trabajo a domicilio (Cline, 1947, pp. 30-31).

En el conocimiento de quienes fueron los inversores en la manufactura textil mexicana existen otras contribuciones que deben considerarse $y$, particularmente, se debe indagar la forma en que se financió a empresarios y cómo evolucionó la fabricación de hilados y tejidos en el trascurso de las primeras cuatro décadas del siglo xix. En primera instancia, es necesario recurrir a la lectura de la obra de Robert Potash (1959), El Banco del Avío de México. El fomento de la industria 1821-1846. La factura de este trabajo partió de la minuciosa consulta de los papeles del primer banco mexicano que promovió e impulsó la reciente industria textil del país. Sin duda, Potash

\section{()(1) $\$$}


estableció en su investigación interesantes pautas para entender que el ramo de hilados y tejidos estuvo impulsado no tan sólo por inversionistas privados, sino también por el financiamiento otorgado por el recién formado Estado mexicano.

En el libro Formación y desarrollo de la burguesía en México siglo XIX, que coordinara Ciro Cardoso (1978), aparecieron investigaciones de historiadores profesionales que abrieron brecha en la historiografía mexicana para conocer las trayectorias de aquellos empresarios que en el transcurso de la centuria decimonónica invirtieron en la industria de los hilados y tejidos. Dicho libro, que cuenta con varias reimpresiones, tiene algunas contribuciones notables. Aparece el trabajo de Guillermo Beato (1978), "La Casa Martínez del Río: del comercio colonial a la industria fabril. 1829-1864. La fábrica Miraflores”. Este ensayo sobresale por advertir que esta casa comercial sobresalió por su extraordinaria cohesión familiar para promover varias actividades económicas en las esferas comercial, financiera, industrial e inmobiliaria (Beato, 1978, p. 58). Además se caracteriza por ser un ensayo que se preocupa por reconstruir las redes de negocios de un comerciante con presencia en varias regiones de México, así como sus vínculos con los gobiernos mexicanos al figurar como tenedor de bonos de la deuda pública en la primera mitad del siglo xix (Beato, 1978, p. 63).

También dicho libro cuenta con la novedosa contribución de Rosa María Meyer (1978), "Los Béistegui, especuladores y mineros". Cabe decir que la autora es pionera en la confección de la genealogía de ese poderoso hombre de negocios después de un detenido estudio de protocolos notariales (pp. 109-114). En este artículo, Meyer (pp. 123-125) mostró también lo que fue la audacia como inversor en la industria textil en las fábricas La Colmena y La Abeja, en los telares del Hospicio de Pobres, así como en la fábrica de lana San Ildefonso en Tlalnepantla.

Otro aporte más que nos interesa del mencionado libro es el escrito por Roberto Hernández Elizondo (1978), "Comercio e industria textil en Nuevo León. 1852-1890. La fábrica de algodón La Fama de Nuevo León, sociedad Gregorio Zambrano, Clausen y Cía., Valentín Rivero”. Su interés radica en que dio pautas para conocer de dónde provenía los capitales de aquellos que forjaron la industria de hilados y tejidos en el noreste de México (pp. 276-280).

\section{()(1) $(9$}


Varios de los estudios sobre los empresarios textiles primero se elaboraron como tesis de doctorado y después lograron un formato de libro. Un ejemplo de ello es la obra de David W. Walker (1991) Parentesco, negocios y política. La familia Martínez del Río en México, 1823-1867. Los planteamientos de Walker se centran en que la procedencia del capital que este empresario invirtió en la manufactura hilados y tejidos tuvieron su origen en la usura. En las primeras décadas del México independiente, la firma Martínez del Río fue una de las más renombradas casas comerciales que fungió como prestamistas de los inestables gobiernos mexicanos. Otro aspecto a destacar del libro de Walker es que en su reconstrucción histórica de la fábrica Miraflores mostró todas aquellas condiciones para establecer en el entonces distrito de Chalco del Estado de México un centro fabril con abasto de algodón y suficientes recursos naturales como agua y bosques. Su importancia radicaba en su cercanía con el mercado consumidor de la ciudad de México, al igual que la infraestructura necesaria para la entrada de materia prima y salida de las manufacturas, así como la fuerza de trabajo para elaborar la manufactura de tejidos de algodón (Walker, 1991, pp. 183-219).

Asimismo, la historiografía de Puebla empezó a contar con varios trabajos de buena factura que se publicaron en las décadas de 1980 y 1990, para dar a conocer a los propietarios y la formación del mundo del trabajo en la zona fabril de ese estado durante los siglos XIX y xx. Aquí se puede incluir las distintas obras de Leticia Gamboa Ojeda, Los empresarios de ayer. El grupo dominante en la industria textil de Puebla 1906-1920 (1985), Mercado de fuerza de trabajo e industria textil. Centro-oriente de México durante el porfiriato (1991). Se cuenta con otro ensayo de Leticia Gamboa en donde se advierte la organicidad corporativa de los inversores en los hilados y tejidos durante el régimen de Porfirio Díaz y que lo presentó en su artículo "Formas de asociación empresarial en la industria textil poblana" (1993). La obra diversa de esta autora inició con el libro La urdimbre y la trama. Historia social de los obreros textiles de Atlixco, 1899-1924 (2001).

Puede decirse también que Leticia Gamboa, en distintos trabajos, se ha preocupado por indagar la especificidad de un grupo de empresarios franceses y, particularmente, los barcelonnettes. El interés de Gamboa por analizar a estos hombres de negocios radica, precisamente, en su activa participación en la industrialización y comercialización textil de Puebla y la comercialización de telas y prendas de vestir orientadas al gran mercado de

\section{()(1) $(9$}


la capital del país. La autora decidió presentar sus avances de investigación en el artículo "Los barcelonnettes en la ciudad de Puebla: Panorama de sus actividades económicas en el porfiriato" (1998), y después los incluyó en un capítulo de libro que intituló: "Nuevas piezas del rompecabezas. Los catorce primeros almacenes de ropa y novedades barcelonnettes en la ciudad de México, 1829-1853" (2011). ${ }^{20} \mathrm{Su}$ aporte es una reconstrucción sobre las peculiaridades de los almacenes capitalinos de ropa y novedades propiedad de los barcelonnettes que hicieron buenos negocios en la zona comercial de la capital del país (Gamboa, 2011, pp. 156-157).

Un antecedente más para conocer a los hombres de negocios que invirtieron en la manufactura textil de Puebla la ofrece Humberto Morales (1999) en su artículo "Esteban de Antuñano y la república de la industria. Su influencia en México a lo largo del siglo xIx". En este ensayo muestra las ideas y acciones que emprendió este fundador de la fábrica textil poblana Constancia Mexicana ya desde el año de 1835. Del mismo modo, se hace un acercamiento al estudio de uno de los hombres de negocios que modernizó la producción textil desde su primer despegue de la industrialización durante las décadas de 1830 a 1850.

Por su parte, Coralia Gutiérrez Álvarez (2000) publicó Experiencias contrastadas. Industrialización y conflictos textiles del centro-oriente de México, 1884-1917. Es un texto que busca historiar los contrastes entre obreros y empresarios en el proceso de modernización del sistema fabril poblano en el último cuarto del siglo xIX, y durante los primeros años de la lucha armada en 1910. Contiene entre sus objetivos la incidencia que tuvieron los empresarios en el mercado regional textil, sus áreas de inversión, la innovación tecnológica que se utilizó en esta rama, así como los conflictos obreros-empresariales en los años de 1806 y 1807 (pp. 81-100).

Se cuenta con estudios sobre los distintos momentos que tuvo el proceso de industrialización textil en la propia capital de la república mexicana como en sus alrededores. Un primer acercamiento sobre la región fabril de

${ }^{20}$ En la confección de la obra, la autora se basó en fuentes primarias provenientes de repositorios del Ayuntamiento de la Ciudad de Puebla, General de Notarías, Registro Público de la Propiedad y del Comercio del Estado, Judicial, y Archivo Histórico de la Cámara de la Industria Textil de Puebla y Tlaxcala, así como del Archivo General de la Nación en sus ramos Gobernación, Presidentes, y Departamento del Trabajo y Fomento.

\section{()(1) $\$$}


San Ángel lo realizó Mario Trujillo Bolio primero en el artículo "La fábrica La Magdalena Contreras" (1997), y después a través del libro Empresariado y manufactura textil en la ciudad de México y su periferia. Siglo XIX (2000). El investigador se interesó en reconstruir en la región textil del Valle de México la trama de la comercialización de hilados, tejidos y ropas, y en qué consistió el desenvolvimiento del espacio productivo en la región. ${ }^{21}$ En la segunda obra señalada, el autor trata de mostrar la especificidad de distintos entornos manufactureros como los obradores, ovillos, tórculos y talleres de sombrerería. Especial atención se les da a las protofábricas citadinas que tuvieron como propósito la fabricación de hilaza y mantas entre las décadas de 1830 y 1850 (Trujillo, 2000, pp. 34-35). De igual modo se estudió los modelos industriales que implementaron los empresarios-fabricantes en los centros fabriles como La Colmena y La Abeja, San Ildefonso, Miraflores, La Fama Montañesa y La Magdalena Contreras (pp. 142-168).

Por otro lado, se cuenta con trabajos específicos sobre los empresarios que aparecieron en la primera década del presente siglo. Lucía Martínez (2001) realizó un interesante ensayo que intituló "Íñigo Noriega Laso. Un emporio empresarial. Inmigración y crecimiento económico (1868-1913)”. La selección que hiciera Martínez no fue casual dado que este hombre de negocios llegó a ser uno de los más poderosos propietarios de la Compañía Industrial de Hilados, Tejidos y Estampados de San Antonio Abad (pp. 40-43). El consorcio no sólo tuvo centros manufactureros en el Distrito Federal, sino también en el estado de México con las fábricas La Colmena, Barrón y Miraflores, esta última en Chalco. También para el caso de Jalisco se publicó el trabajo de Sergio Valerio (2003), "Empresarios españoles en Guadalajara durante el porfiriato: La Casa Fernández del Valle". Igualmente, existen otros estudios que dan cuenta de empresarios que invirtieron en la manufactura textil. Nos referimos al estudio de Claudia Pardo Hernández (2008) en su libro Inmigrantes y comercio. Los españoles y su estructura social en la ciudad de México en 1848 y, también, a Carlos Herrero (2004), en su texto Los empresarios

${ }^{21}$ En ambos trabajos se reconstruyen las zonas fabriles de Chalco, Tlalnepantla, San Ángel y Tlalpan, con documentación proveniente del Archivo General de la Nación, Archivo Histórico Banamex, Archivo Judicial del Tribunal Superior de Justicia, Archivo de Notarías de la Ciudad de México y el Archivo Histórica del Agua.

\section{(ㄷ)(1) $(3$}


mexicanos de origen vasco y desarrollo del capitalismo en México, 1880-1950. Este último trabajo nos muestra, a partir de la indagación en los papeles de empresarios existentes en el Archivo de Indianos (Colombres), España, la forma como este grupo poderoso de españoles establecidos en distintos estados, como Veracruz, Michoacán, Puebla y en la Ciudad de México, invirtieron en varias fábricas textiles del porfiriato tardío. El estudio se refiere a los casos de los hermanos Zaldo, Antonio Basagoiti, Barrenche, Martino, Arechaga, José Goyarzu, y Arzumendi, mismos que crearon distintos negocios en la manufactura y comercialización de hilados, tejidos y ropas, al igual que los inversores franceses en México.

La historiografía mexicana al iniciar el siglo xxi resultó ser muy prolífica en estudios de los hombres de negocios con inversiones en la industria de los hilados y tejidos en México. En el libro editado por Mario Trujillo Bolio y José Mario Contreras (2003), Formación empresarial, fomento industrial y compañías agrícolas en el México del siglo XIX, el objetivo fue centrarse en los inversores de la industria textil en México. En los trabajos de esta obra se abordan las actitudes y negocios empresariales, la manera en que llegaron a interesarse los capitales en la industria de la lana y algodón y, al mismo tiempo, cómo los dueños de las compañías, además de la producción fabril, orientaron otros negocios para la venta de los hilados, tejidos y ropa, ya fuese en la generación de energía eléctrica o en el establecimiento de fraccionamientos urbanos en las inmediaciones de los centros manufactureros. ${ }^{22}$ Finalmente, se reconstruye cómo en tiempos de crecimiento en el porfiriato surgieron nuevas inversiones, se dieron notables cambios en las plantas productivas con las renovadas tecnologías y maquinaria y equipo importados del extranjero. De este libro hay que destacar dos contribuciones que son importantes. Una que se refiere a los fabricantes de textiles

${ }^{22}$ En este libro se dieron a conocer varios ensayos sobre compañías que invirtieron en la industria textil en distintos estados del país y los trabajos utilizaron como base para los estudios fuentes notariales, municipales, archivos estatales y el Archivo Histórico del Agua. Sin duda, es un bien logrado intento por presentar la orientación que siguieron en el noreste de México las experiencias empresariales y las especificidades de las inversiones. Otro aporte de este libro lo presentaron Mario Camarena y Mario Trujillo Bolio (2003) en el artículo, "Empresarios, comerciantes, hacendados y fraccionadores: los industriales textiles de 1850 a $1940 "$.

\section{()(1) $\$$}


en Oaxaca de Carlos Sánchez que tituló "Don José Zorrilla (1829-1827). 'El Tenorio oaxaqueño" (2003). Este estudio muestra no sólo cómo surgieron las fábricas San José y Xía, y se constituyeron la sociedad Zorrilla y Jacobo Grandisson que invirtió en la fábrica de algodón Vista Hermosa en Etla, Oaxaca. El artículo es una reconstrucción histórica sobre las fábricas textiles La Escoba en Zapopan, Río Blanco, y Atemajac. El autor señala las distintas operaciones que llevaron a la adquisición de estos centros fabriles, sobresalen no tan sólo los hermanos Fernández como propietarios, sino otros socios, renombrados capitalistas como Manuel Jesús Olasaguirre, Manuel Escandón, Julio Moyssard y la Barrón, Forbes y Cía. El segundo trabajo sobresaliente de dicho libro es el de Humberto Morales (2003), "Los empresarios y la política fiscal de fomento industrial en Puebla del porfiriato a la revolución"; su importancia radica en que incursionó en un tema poco estudiado por la historiografía y vinculado con la política arancelaria del estado y sus relaciones con las empresas manufactureras más sobresalientes poblanas como El Mayorazgo, Patriotismo, La Constancia, La Economía, Molino de Santo Domingo, La Teja, y las establecidas en la zona de Atlixco como La Concepción y La Carolina.

Cabe decir que los estudios sobre compañías textiles en Veracruz continúan a partir del trabajo que hiciera Erika Galán Amaro (2012), primero en su tesis doctoral y después ya en formato de libro. Nos referimos al estudio Estrategias y redes de los empresarios textiles de la Compañia Industrial Orizaba $S$. A. 1889-1930. La reconstrucción histórica destaca por desentrañar las redes de negocios de los empresarios barcelonnettes durante algunos momentos históricos: el porfiriato tardío, en la revolución mexicana, y durante la primera guerra mundial. ${ }^{23}$ En consecuencia, Galán Amaro logró discernir cuál fue la organicidad empresarial en donde estuvieron implícitos los vínculos matrimoniales, las relaciones amistosas y económicas de estos empresarios que también tuvieron acciones en las instituciones bancarias, fundidora Monterrey y la compañía papelera San Rafael.

${ }^{23}$ Resulta interesante este trabajo, pues se elaboró con documentación proveniente de los archivos notariales, del Registro Público de la Propiedad de Orizaba y Municipales de Orizaba y Río Blanco.

\section{()(1) $(9$}




\section{LISTA DE REFERENCIAS}

Bazant, J. (1964). Evolución de la industria textil poblana (1554-1845). Historia Mexicana, XIII(2), 473-516. Recuperado de http://historiamexicana.colmex.mx/index. php/RHM/article/view/963/854

Beato, G. (1978). La Casa Martínez del Río: del comercio colonial a la industria fabril, 1829-1864. La Fábrica Miraflores. En C. Cardoso (coord.), Formación y desarrollo de la burguesía en México siglo XIx. México: Siglo Veintiuno Editores.

Beato, G. (2003). La industria textil fabril en México. I. 1830-1900. En M. Trujillo Bolio y J. M. Contreras (eds.), Formación empresarial, fomento industrial y compañías agrícolas en el México del siglo XIx. México: CIEsAs.

Beato King, R. (2003). La industria textil fabril en México. II. 1900-1910. En M. Trujillo Bolio y J. M. Contreras (eds.), Formación empresarial, fomento industrial y compañías agrícolas en el México del siglo XIX. México: CIESAs.

Becerril, J. G. (2011a). Las fábricas de San Antonio Abad y San Ildefonso (1842-1910). Producción y tecnología en la manufactura de hilados y tejidos de algodón y lana. México: INAH.

Becerril, J. G. (2011b). Innovación tecnológica en la mecanización de la industria textil del Valle de México 1880-1910. Transformaciones y permanencias productivas en las fábricas de hilados y tejidos de algodón. (Tesis de doctorado). UAM-Iztapalapa, México.

Berg, M. (1987). La era de las manufacturas 1700-1820. Una nueva historia de la revolución industrial británica. Barcelona: Editorial Crítica.

Berneker, W. L. (1992). De agiotistas y empresarios. En torno de la temprana industrialización mexicana del siglo XIX. México: Universidad Iberoamericana.

Camarena Ocampo, M. y Trujillo Bolio, M. (2003). Empresarios, comerciantes, hacendados y fraccionadores: los industriales textiles de 1850 a 1940. En M. Trujillo Bolio y J. M. Contreras (eds.), Formación empresarial, fomento industrial y compañias agrícolas en México del siglo XIX. México: CIESAs.

Carabarín Gracia, A. (1984). El trabajo y los trabajadores del obraje en la ciudad de Puebla, 1700-1710. Puebla: Universidad Autónoma de Puebla (Cuadernos de la Casa Presno, 1).

Carabarín Gracia, A. (1992). Región y mercado colonial: las coyunturas de los obrajes poblanos entre los siglos XVI y XVIII. En La ciudad y el campo en la historia de México. Memoria de la VI Reunión de Historiadores Mexicanos y Norteamericanos (pp. 803-813). México: UnAM.

\section{()(1) $\$$}


Cardoso, C. (coord.) (1978). Formación y desarrollo de la burguesía en México siglo XIX. México: Siglo Veintiuno Editores.

Carrera Stampa, M. (1939). Los obrajes de indígenas en el virreinato de la Nueva España. Actas del XXVII Congreso Internacional de Americanistas. México.

Chávez Orozco, L. (1936). El obraje, embrión de la fábrica. México: Publicaciones de la Secretaría de Economía Nacional.

Chávez Orozco, L. (1938). Historia económica y social de México: ensayo de interpretación. México: Ediciones Botas.

Chávez Orozco, L. y Florescano, E. (1965). Agricultura e industria textil en Veracruz. Xalapa: Universidad Veracruzana.

Cline, H. F. (1947). The "Aurora Yucateca" and the Spirit of Enterprise in Yucatan, 1821-1847. The Hispanic American Historical Review, XXVII(1), 30-60. Recuperado de http://www.jstor.org/stable/2508590

Cosío Villegas, D. (dir.) (1985). Historia moderna de México. El porfiriato: vida económica. México: Editorial Hermes

Galán Amaro, E. (2012). Estrategias y redes de los empresarios textiles de la Compañía Industrial Orizaba S. A. 1889-1930. Madrid: Editorial Academia Española.

Gamboa Ojeda, L. (1985). Los empresarios de ayer. El grupo dominante en la industria textil en Puebla 1906-1929. México: BUAP.

Gamboa Ojeda, L. (octubre, 1991). Mercado de fuerza de trabajo e industria textil. El centro-oriente de México durante el porfiriato. Siglo xIx. Cuadernos de Historia, año I(1).

Gamboa Ojeda, L. (1993). Formas de asociación empresarial en la industria textil poblana. En L. Ludlow y J. Silva Riquer (comps.), Los negocios y las ganancias de la colonia al México moderno. México: Instituto Mora/IIH-UNAM.

Gamboa Ojeda, L. (1998). Los barcelonnettes en la ciudad de Puebla: Panorama de sus actividades económicas en el porfiriato. En J. Pérez Siller (coord.), México-Francia. Memoria de una sensibilidad común siglos XIX-XX. México: BUAP/El Colegio de San Luis/CEMCA.

Gamboa Ojeda, L. (2001). La urdimbre y la trama. Historia social de los obreros textiles de Atlixco, 1899-1824. México: FCE.

Gamboa Ojeda, L. (2011). Nuevas piezas del rompecabezas. Los catorce primeros almacenes de ropa y novedades barcelonnettes en la ciudad de México, 1829-1853. En L. Gamboa, G. Rodríguez y E. Munguía (coords.), Franceses. Del México colonial al contemporáneo. México: Instituto de Ciencias Sociales y Humanidades-BUAP.

\section{()(1) $\$$}


García Díaz, B. (1981). Un pueblo fabril del porfiriato: Santa Rosa, Veracruz, México. México: FCE (SepOchentas).

García Luna, M. (1984). El movimiento obrero en el Estado de México. Primeras fábricas, obreros y huelgas (1830-1910). México: UAEM.

García Luna, M. (1998). Los orígenes de la industria en el Estado de México, 1830-1930. México: Instituto Mexiquense.

Gómez-Galvarriato, A. (1998). Industrial development in time under institutional frailty: the Mexican cotton textile industry in the 19th century. Documento de Trabajo, 107, 1-36. México: CIDE.

Gómez-Galvarriato, A. (1999). The impact of the revolution: business and labor in the Mexican textile industry, Orizaba, Veracruz, 1900-1930. (Tesis de doctorado). Universidad de Harvard.

Gómez-Galvarriato, A. (2013). Industry and revolution. Social and economic change in the Orizaba valley, Mexico. Massachusetts: Harvard Historical Studies.

González Jácome, A. (comp.) (1991). La economía desgastada. Historia de la producción textil en Tlaxcala. México: Universidad Autónoma Metropolitana/Universidad Iberoamericana.

Greenleaf, R. E. (1967). The obraje in the late Mexican colony. The Americas, xxIII(3), 227-250. DoI: http://dx.doi.org/10.2307/980468

Gutiérrez Álvarez, C. (2000). Experiencias contrastadas. Industrialización y conflictos textiles del centro-oriente de México, 1884-1917. México: Colmex/BuAp.

Hernández Elizondo, R. (1978). Comercio e industria textil en Nuevo León, 1852-1890. En C. Cardoso (coord.), Formación y desarrollo de la burguesía en México, siglo XIX. México: Siglo Veintiuno Editores.

Herrero, C. (2004). Los empresarios mexicanos de origen vasco y desarrollo del capitalismo en México, 1880-1950. México: UAM-Iztapalapa/Plaza y Valdés.

Keremitisis, D. (1973). La industria textil mexicana en el siglo XIX. México: FCE (SepSetentas).

Koprivitza Acuña, M. (coord.) (enero-marzo, 2008). La industria textil en Tlaxcala. Tlacuilo. Revista del Archivo del Estado de Tlaxcala, 4.

Maillefert, E. (1992). Directorio del comercio del imperio mexicano [edición facsimilar de la de 1867]. México: Instituto Mora.

Martínez Moctezuma, L. (2001). Íñigo Noriega Laso. Un emporio empresarial. Inmigración y crecimiento económico (1868-1913). México: UAM-Iztapalapa (Cuadernos de Historia Empresarial).

\section{()(1) $(2$}


Meyer, R. M. (1978). Los Béistegui, especuladores y mineros. 1830-1869. En C. Cardoso (coord.), Formación y desarrollo de la burguesía en México, siglo xIx. México: Siglo Veintiuno Editores.

Miño Grijalva, M. (1989). ¿Protoindustria colonial? Historia Mexicana, xxxviII(4), 793-818. Recuperado de http://www.jstor.org/stable/25138255

Miño Grijalva, M. (1990). Obrajes y tejedores en Nueva España, 1700-1810. Madrid: Instituto de Cooperación Iberoamericana.

Miño Grijalva, M. (1993a). La manufactura colonial. La constitución técnica del obraje. México: Colmex/Jornadas 123.

Miño Grijalva, M. (1993b). La protoindustria colonial hispanoamericana. México: FCE/ Colmex.

Mora Vázquez, T. (2012). Testimonios de Tizapán. Memoria y olvido de un pueblo originario de la ciudad de México. México: INAH.

Morales Moreno, H. (1987). La expansión industrial del valle de Atlixco de fines del siglo xIx. El Caso de la fábrica textil de Metepec de la ciAsA. VI Encuentro de la Formación del Capitalismo en México. Puebla, 21-23 octubre.

Morales Moreno, H. (1999). Esteban de Antuñano y la república de la industria. Su influencia en México a lo largo del siglo xix. En W. Fowler y H. Morales (coords.), El conservadurismo mexicano en el siglo XIX. Puebla: BUAP/Saint-Andrews University.

Morales Moreno, H. (2003). Los empresarios y la política fiscal de fomento industrial en Puebla del porfiriato a la revolución. En M. Trujillo Bolio y J. M. Contreras (eds.), Formación empresarial, fomento industrial y compañías agrícolas en México del siglo XIX. México: CIESAs.

Morales Moreno, H. (2009). La industria textil mexicana en el ciclo de las exportaciones latinoamericanas: 1880-1930. Política fiscal y de fomento en la encrucijada de la revolución. Revista de la Industria Argentina y Latinoamericana, año 3(5). Recuperado de http://ojs.econ.uba.ar/ojs/index.php/H-ind/article/view/445/816

Oropeza Villavicencio, E. A. (2001). Del obraje de Contreras a la fábrica de hilados y tejidos La Magdalena (400 años de testimonio textil). (Tesis de licenciatura). ENAH, México.

Pardo Hernández, C. (2008). Inmigrantes y comercio. Los españoles y su estructura social en la ciudad de México en 1848. México: Centro de Estudios Históricos Internacionales/UAM-Iztapalapa.

Peña, Sergio de la (1975). Formación del capitalismo en México. México: IIs-UnAM/Siglo Veintiuno Editores.

Potash, R. (1959). El Banco del Avío de México. El fomento de la industria 1821-1846. México: FCE.

\section{()(1) $(2$}


Ramos Escandón, C. (2004). Industrialización, género y trabajo femenino en el sector textil mexicano: el obraje, la fábrica y la compañía industrial. México: CIEsAs.

Rosas Salas, S. (2013). Agua e industria en Puebla. El establecimiento de la fábrica textil La Covadonga, 1889-1897. Relaciones. Estudios de Historia y Sociedad, XxxIV(136), 223-264. Recuperado de http://www.revistarelaciones.com/files/revistas/136/pdf/ RosasSalas.pdf

Rosenzweig, F. (1985). La Industria. En D. Cosío Villegas (dir.), Historia moderna de México. El porfiriato: Vida económica. México: Editorial Hermes.

Salvucci, R. J. (1992). Textiles y capitalismo en México. Una historia económica de los obrajes, 1539-1840. México: Alianza Editorial.

Sánchez, C. (2003). Don José Zorrilla Trápaga (1829-1897). "El Tenorio oaxaqueño". En M. Trujillo Bolio y S. M. Contreras Valdez (eds.), Formación empresarial, fomento industrial y compañías agrícolas en el México del siglo XIX. México: CIESAs,

Super, J. (1976). Queretaro obrajes: industry and economy in early provincial Mexico, 1600-1810. The Hispanic American Historical Review, 56(2), 197-216. Recuperado de http://www.jstor.org/stable/2514324

Terán Trillo, D. Y. (2012). El castillo de La Fama. Antiguo molino de trigo y fábrica de hilados y tejidos en Tlalpan, 1612-1936. México: INAH.

Thomson, G. (1989). Puebla de los Ángeles. Industry and society in a mexican city, 17001850. Boulder: Westview Press.

Thomson, G. (1999). Continuidad y cambio en la industria manufacturera mexicana, 1800-1870. En A. Gómez-Galvarriato (ed.), La industria textil en México. México: Instituto Mora.

Trujillo Bolio, M. (1997). La fábrica La Magdalena Contreras. En C. Marichal y M. Cerruti (comps.), Historia de las grandes empresas en México 1850-1939 (pp. 245-274). México: FCE/Universidad Autónoma de Nuevo León.

Trujillo Bolio, M. (2000). Empresariado y manufactura textil en la ciudad de México y su periferia, siglo XIX. México: CIESAs.

Trujillo Bolio, M. y Contreras, J. M. (eds.) (2003). Formación empresarial, fomento industrial y compañías agrícolas en el México del siglo XIX. México: CIESAs.

Uribe Salas, J. A. (1983). La industria textil en Michoacán 1840-1910. México: Universidad Michoacana de San Nicolás de Hidalgo.

Valerio, S. (2003). Empresarios españoles en Guadalajara durante el porfiriato: la Casa Fernández del Valle. En M. Trujillo Bolio y J. M. Contreras (eds.), Formación empresarial, fomento industrial y compañías agrícolas en el México del siglo xIx. MéxiCO: CIESAS.

\section{(이요 $(3$}


Viqueira Landa, C. (1983). Los orígenes de la industria textil en México. Ingeniería, LIII(4), 91-105.

Viqueira, C. y Urquiola, J. I. (1990). Los obrajes en La Nueva España, 1530-1630. México: Conaculta.

Vizcarra Rubio, J. (2011). Estructura, funcionamiento y rentabilidad de la empresa textil tepiqueña y de otras regiones del México porfiriano. (Tesis de maestría). Facultad de Economía-UnAm.

Walker, D. W. (1991). Parentesco, negocios y política. La familia Martínez del Río en México, 1823-1867. México: Alianza Editorial.

\section{OTRAS FUENTES}

\section{Bibliografía}

Camarena Ocampo, M. (2001). Jornaleros, tejedores y obreros. Historia social de los trabajadores textiles de San Ángel (1850-1930). México: Plaza y Valdés.

Castañeda, C. (1980). Sobre una fábrica textil u obraje establecido en Guadalajara en el siglo xVIII. Boletín del Archivo Histórico de Jalisco, 4, 13-16.

Cline, H. F. (1968). La industria de transformación mexicana (1821-1910). Memorias de la Academia Mexicana de la Historia, XXVII(102), 219-224.

Gamboa Ojeda, L. (1999). Fragilidad institucional y subdesarrollo: La industria textil mexicana en el siglo xIx. En A. Gómez-Galvarriato (coord.), La industria textil en México (pp. 142-182). México: Instituto Mora.

Gómez-Galvarriato, A. (coord.) (1999). La industria textil en México. México: Instituto Mora.

Ramírez Rancaño, M. (1987). Burguesía textil y política en la revolución mexicana. México: Instituto de Investigaciones Sociales-UnAM.

Salvia Spratte, A. (1989). Los laberintos de Loreto y Peña Pobre. México: Ediciones el Caballito.

Thomson, G. (1986). The coton textile industry in Puebla during the eighteenth and early nineteenth centuries. En N. Jacobsen y H. J. Puhle (eds.), The Economies of Mexico and Peru during the late colonial period, 1760-1810 (pp. 169-202). Berlín: Colloquium Verlag.

Trujillo Bolio, M. (1997). Operarios fabriles en el Valle de México. Espacio, trabajo, protesta y cultura obrera. México: Colmex/ciesas.

\section{(ㄷ)(1) $(3$}

